\title{
Identification and analysis of the elements and functions integrable in integrated management systems
}

\author{
Thaís Vieira Nunhes, Luis César F. Motta Barbosa, Otavio Jose de Oliveira* \\ São Paulo State University - UNESP, Brazil
}

\section{A R T I C L E I N F O}

\section{Article history:}

Received 29 June 2016

Received in revised form

14 October 2016

Accepted 26 October 2016

Available online 27 October 2016

\section{Keywords:}

Integrated management systems

Certifiable management systems

ISO 9001

ISO 14001

OHSAS 18001

\begin{abstract}
A B S T R A C T
The purpose of this article is to characterize and discuss the elements and functions most commonly integrated in Brazilian companies certified by the management systems ISO 9001, ISO 14001 and OHSAS 18001 and to identify the benefits and difficulties from integration. This study contributes with suggestions of achievements to overcome the major difficulties and challenges faced during the integration process. In order to support the research, the theoretical framework was conducted comprising certifiable management systems (ISO 9001, ISO 14001 and OHSAS 18001) and Integrated Management Systems. The study was based on a qualitative approach supported by an analysis in the practical context, which examined the results of fourteen case studies in Brazilian industrial companies. The development of the research involved three visits in each one of the companies studied. The results indicated the most integrated elements and functions in the companies studied are the high management responsibility, work instructions, control of documents and records, internal communication and structure and accountability. Further, the benefits of integration were the improvement in efficiency of operations and internal communication, greater agility in the decision-making process, increase in the quality of goods and services produced or provided and increase in reliability of the products and processes. The main difficulties were the complexity of integration process and the high amount of human and financial resources spent on implementation.
\end{abstract}

๑) 2016 Elsevier Ltd. All rights reserved.

\section{Introduction}

Economic globalization and the intensification of competitiveness has led many organizations to adopt management tools that enable them to obtain high-quality products and processes without harming the environment and employees' life quality (Simon et al., 2014a,b). Therefore, companies have implemented ISO 9001 Quality Management Systems (QMS), ISO 14001 Environmental Management Systems (EMS) and OHSAS 18001 Safety Management System and Occupational Health (OHSMS) as a solution to achieve these objectives (Sampaio and Neves, 2012).

According to ISO Survey (2015), in 2014 there were 1,138,155 certifications worldwide related to ISO 9001 and 324,148 related to ISO 14001. Moreover, according to OHSAS (2016), in 2015 92,315 certifications related to OHSAS 18001 distributed in 127 countries around the world were estimated. In this context, it is noteworthy that the implementation of certifiable management systems has

\footnotetext{
* Corresponding author.

E-mail address: otaviodeoliveira@uol.com.br (O.J. de Oliveira).
}

become a common practice among different types of organizations which seek for greater competitiveness. This tendency, in turn, has amplified another phenomenon: the phenomenon of the integrated management system (Oliveira, 2013).

The certifiable management systems can be integrated with each other and also with other systems (Oliveira, 2013). In this regard, many organizations have opted to implement an Integrated Management System (IMS) covering ISO 9001, ISO 14001 and OHSAS 18001 as an alternative to optimize efforts and resources (Sampaio et al., 2012; Oliveira, 2013).

The standards ISO 9001, ISO 14001 and OHSAS 18001, which are the subject of this study, directly or indirectly, include elements in common, such as process control systems, human resources, information, documents, design, production, and the distribution of products and services to meet the needs of customers and the company (Bernardo et al., 2009). According to Oliveira (2013), these similarities make them synergetic and favorable to integration.

In view of this situation, the research question that guides this article is to investigate the elements and functions that make up the IMS in the companies studied. In this way, the aim of this study is to characterize and discuss the elements and functions most 
commonly integrated in companies certified by ISO 9001, ISO 14001 and OHSAS 18001 and identifying the benefits and difficulties from integration. This study contributes with suggestions of achievements to overcome the major difficulties and challenges faced during the integration process.

It's worth pointing out that other works in this field deal with it from a more general view, without consider a detailed focus as will be presented in this article.

The article is organized into five sections. The first one includes the introduction, purpose and structure of the article. The following section presents the theoretical framework about the three most used management standards worldwide and about integrated management systems. In the third section the method and research instruments used for the study are presented. In the fourth section the results of fourteen case studies are presented and analyzed. In the fifth section the findings of this work is presented, highlighting the research limitations, its scientific and applied contributions, and proposals for future works related to the topic.

\section{Synthesis of the theoretical framework}

In this section a brief theoretical review of ISO 9001 QMS, ISO 14001 EMS and OHSAS 18001 OHSMS is conducted, as well as of the integrated management systems.

\subsection{Certifiable management systems}

The increase in industrial accidents and loss of life, material and environmental issues has led industrial organizations to use more and more management systems certification voluntarily (Sampaio and Neves, 2012; Santos et al., 2013; Oliveira, 2013). Among the most used certifiable management systems worldwide are ISO 9001 QMS, ISO 14001 EMS and OHSAS 18001 OHSMS (Sampaio et al., 2012; Vrellas and Tsiotras, 2015).

ISO 9001 is a certifiable standard accepted worldwide and, consequently, the most effective relationship between supplier and customer (Vrellas and Tsiotras, 2015). The purpose of the ISO 9001 standard is to improve the performance of the organization, as well as ensure the customers' satisfaction (Kim et al., 2012).

ISO 9001 presents auditable requirements for a quality management system focused in a process approach and based on the PDCA (Plan, Do, Check and Action) cycle (Sumaedi and Yarmen, 2015). The continuing fulfillment of ISO 9001 requirements provides the standardization of processes, which help companies to improve the quality of products, services and increase market share with greater financial returns (Vrellas and Tsiotras, 2015; Weckenmann et al., 2015). Therefore, the organization that participates in a continuous process of ISO 9001 certification realizes its benefits by demonstrating compliance with the standard (Pronovost and Marsteller, 2014).

Campos et al. (2015) has emphasized the aim of ISO 14001 is to help companies to continuously improve their environmental performance, through an approach based on the PDCA cycle, while complying with all applicable laws. Due to its voluntary nature, the ISO 14001 enables organizations to be responsible for setting their own goals and performance measures, and it provides them assistance to accomplish their objectives and aims, as well as to help in meetings and in monitoring and measurement activities (Searcy et al., 2012; Ivanova et al., 2014).

According to Lo et al. (2014), organizations recognize the need to monitor and improve the performance of occupational health and safety, concerned with OHSMS requirements. In this context, an international collaboration called Occupational Health and Safety Assessment Series (OHSAS) was formed to create a unified approach (Lo et al., 2014).
The OHSMS is a management system that covers aspects of occupational health and safety, providing a systematic way to identify hazards and control risks which workers or outsourced are exposed, ensuring that they are effectively controlled (Abad et al., 2013; Lo et al., 2014). Like all management systems, the OHSMS promotes system's goals, planning and setting of procedures to measuring and analyze performance. It can also be perceived in the essence of an organization, making them part of their culture and the way people perform their work (Rebelo et al., 2014).

OHSAS 18001 can be aligned with others management systems, such as ISO 9001 and ISO 14001. Historically, many organizations start with the quality management system ISO 9001, and then add the requirements of ISO 14001 EMS (Oliveira, 2013). Therefore, this is the reason why many organizations have begun implementing all three standards at once, in order to minimize cost and disturbances (Qi et al., 2013).

\subsection{Integrated management system}

IMS deals about the integration of three management systems most implemented by organizations around the world, which are QMS's, EMS's and OHSMS's (Oliveira, 2013). There are different definitions of IMS, however, it is clear that the concept embedded in these settings is convergent, since the system is a set of interacting and interdependent parts that form a whole unit with a particular purpose and perform a particular function generating one or more results. Therefore, a truly integrated system is one that combines management systems with a focus on process view and approach of systems that make it possible to put all the practices and relevant management standards in a single system (Sampaio et al., 2012; Simon et al., 2012, Simon et al., 2014a,b; Rebelo et al., 2014).

The integration of certifiable management systems can qualify companies, enabling their participants to have higher productivity at lower cost, while preserving their employees' health and the environment (Wening and Refflinghaus, 2015; Kim et al., 2014). In addition, several organizations consider that an IMS is an excellent opportunity to reduce costs, whereas those that maintain separate systems or some programs and actions that overlap can generate unnecessary expenses (Sampaio et al., 2012; Oliveira, 2013; Ferrón and Darnall, 2016).

Bernardo et al. (2015) carried out a detailed literature review regarding the benefits of IMSs. The analysis considered a comparison between the IMS benefits and the benefits obtained through the individual implementation of ISO 9001 and ISO 14001 standards. The results indicated the IMS benefits most analyzed by researchers are improved efficiency profitability, customer satisfaction, relationship with staff, and image. Furthermore, the authors highlighted the integration of MSs allows achieving more benefits than if they are managed separately (Ferrón and Darnall, 2016).

The integration of certifiable management systems is proposed due the similarities that the structure of ISO 9001 QMS, ISO 14001 EMS and OHSAS 18001 OHSMS share concerning the management policy; planning; implementation and operation; performance evaluation; improvement and critical analysis (Rebelo et al., 2014; Wening and Refflinghaus, 2015). Oliveira (2013) highlighted the process of integrating certifiable management systems must be subjected to the study of similarities, complementarities and contradictions of the standards. In addition, Rebelo et al. (2014) has pointed out the analysis of similarities of these requirements compatible promotes the integration and it can occur through the association with the phases of the PDCA cycle.

According to Oliveira (2013), the process of integration has to be conducted based on structural elements that need to be firstly integrated in order to guide all actions and resources in a common 
direction. These structural elements are: scope, policy, objectives, and responsibilities.

Corroborating, Bernardo et al. (2009), who analyzed the integration level of the IMSs ina sample of 435 Spanish companies, concluded that organizations begin the integration "with the most strategic goals, documentation and procedures (policy, objectives and manual in the case of the goals and documentation, and record control, internal audits and internal communication for procedures), integrating operations and tactics later on".

As can be noted, information about the elements that are effectively integrated in an IMS is commonly presented secondarily in studies that present models of integration and approaches about the levels of integration which an IMS presents. Thus, based on these works, we found that the structural items of an IMS are the following: objectives and targets; manuals; policies; structure and responsibilities; the management representative; work instructions; document and record control; formation; internal communication; emergency plans; performance indicators; acquisition; non-compliance treatment; inspection equipment control; measuring and testing; preventive and corrective actions; internal and external audits; and critical analysis meetings (Sampaio et al., 2012; Oliveira, 2013; Rebelo et al., 2014).

\section{Research method}

The article was conducted through a qualitative approach and based on fourteen case studies. The research flow can be seen in Fig. 1.

The qualitative study was chosen to conduct this study because it enables to interpret the observed phenomenon. Its objectives are observation, description, understanding and meaning (Jupp, 2006; Kothari, 2013; Yin, 2014). A quantitative approach was a feasible alternative, however, a qualitative approach was considered more appropriated because it provides more detailed results.

Stravos and Westberg (2009) highlighted multiple case studies provide a rich set of data due its simultaneous work that involve multiple sources of evidence and different situations. Thus, aiming to obtain consistent results, multiple case studies were performed on natural work environments, which were used as direct source for data collection.

The companies were selected according to the following criteria: they agreed to participate in the study; they have implemented certifiable management systems, such as ISO 9001, ISO 14001 and OHSAS 18001; they know the potential and existing types of integration; and they have, at least, one type of integration between the systems. Additionally, we sought by companies at different levels of integration, some more inchoate, other medians and other more advanced states.

For didactic reasons, this study differs the concepts of IMS tools and programs. IMS tools act to identify problems and their relatedcauses, indicating whether there is consistency in data, information and consequently in decision making (Guikema and Milke, 1999). On the other hand, IMS programs represent investments not only in the employees' working environment, but also on the quality of life as a whole, avoiding waste, reducing costs and increasing productivity, in addition of innovation in the management of the company's routine, developing its employees and also allowing the management of intellectual capital (Guikema and Milke, 1999).

The data collection instruments involved asking the object of study direct questions from a questionnaire. It can also be classified as direct questioning of people whose behavior we want to know (Jupp, 2006; Yin, 2014). The interview conducted to accomplish this study was directed mostly to the top management representative, however, in order to verify if the speech of senior management was

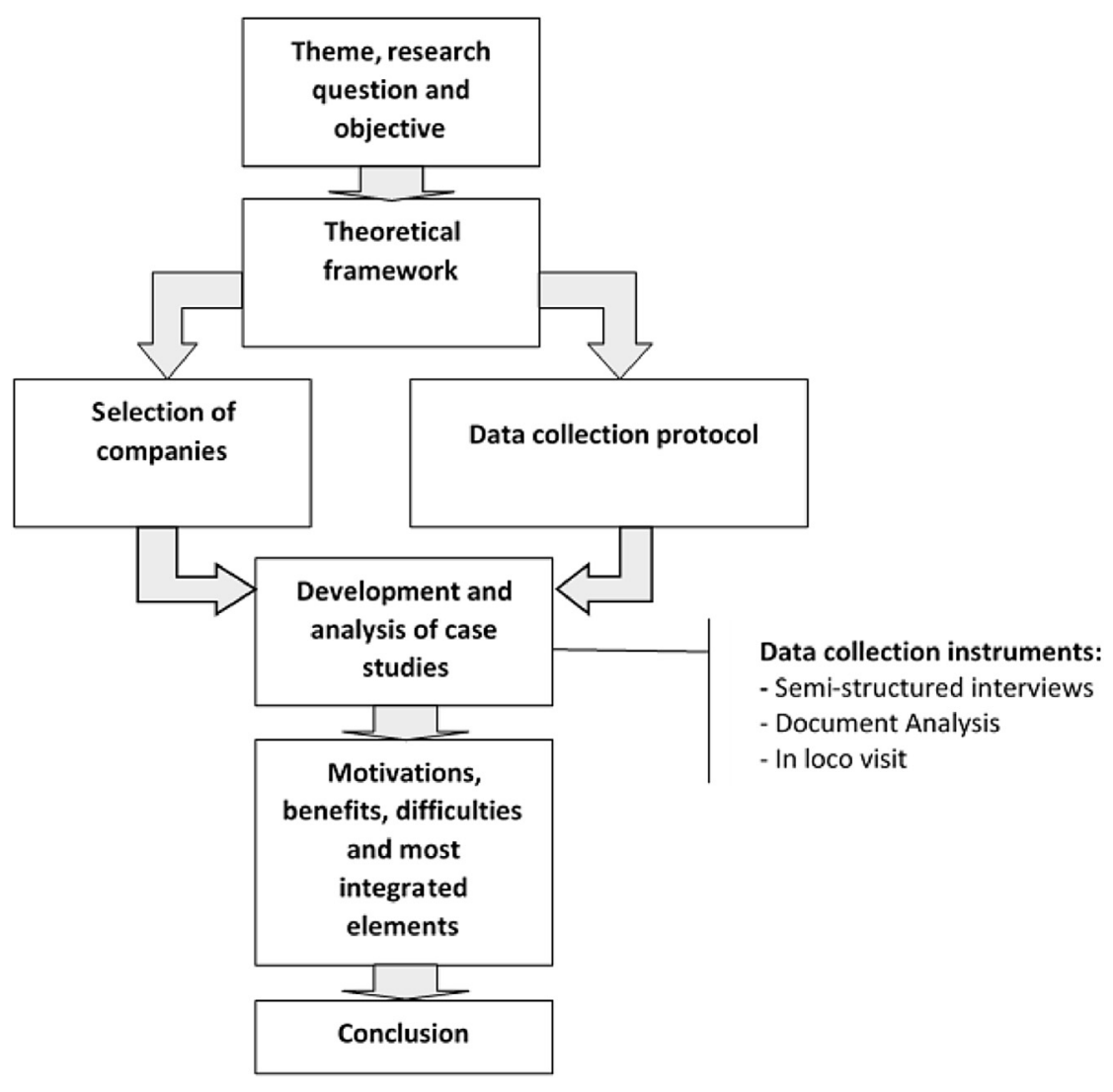

Fig. 1. Research flow diagram. 
indeed perceived by the lower hierarchical levels, specific issues related to the perception of implementation results of management systems in an isolated and integrated way were directed to production managers and key employees in the processes, as appropriate.

The data collection was accomplished via some instruments: a) semi-structured interviews with the Top Management Representative TMR, production managers and selected key employees; b) in loco observation (at least three visits to each company), and c) document analysis, including IMS manuals and/or manuals for each of the separate systems, work instructions and records (Yin, 2014).

Under these circumstances, the script of the semi-structured interview was designed based on the theoretical framework and in researches of the authors. Subsequently, it was revised and approved by three engineers with experience on IMS.

Therefore, the analysis of the elements and existing integrable functions in the IMS's frame was developed based on the theoretical framework, on the results of multiple case studies and in the experiences of the authors. None model was developed or applied.

\section{Case studies}

In this section the main results of the case studies will be presented and analyzed. In the light of a theoretical review, first, analysis regarding IMS motivations, benefits and difficulties of implementation as well as regarding each system separated will be presented, once it will characterize the companies studied and enable, subsequently, the identification of the major elements and integrable functions.

Ensuring confidentiality regarding the companies studied (some of them are well known) they were named by letters in alphabetical sequence from $A$ to $\mathrm{N}$. Eleven of the fourteen companies surveyed are large and three are small and midsize. Thirteen of them have revenues above US\$ $25.000 .000,00$ per year and only one has less than this value. Only two do not export. All fourteen studied companies have facilities in Brazil. The distribution of the companies studied according to their activity sector is shown in Fig. 1.

As can be seen in Fig. 2, the companies were distributed in various sectors, especially the automotive. Moreover, the analysis of the case studies undertaken enabled identifying the motivations, benefits and difficulties related to ISO 9001 (Table 1), ISO 14001
(Table 2) and OHSAS 18001 (Table 3).

The main motivation for the implementation of ISO 9001 is related to the companies' self-assessment. The results showed that companies have chosen to develop and implement this system on the basis of real awareness of the existence of opportunities for internal and external gains, improvement in their designs, processes and products. It is an important information because the motivation based only on competing pressures or "fad" can lead organizations to dubious ways, thereby hindering the development of their IMS.

The most common benefit perceived from the implementation of ISO 9001 QMS in all companies studied was the improvement in the organizational culture. Other benefits frequently observed were: improvement in the company's image, the quality of processes, internal communication, relations with customers and operational efficiency.

Regarding the difficulties faced by companies during the ISO 9001 implementation process, a scenario better than the one indicated by previous studies was observed. The employee resistance was a difficulty observed previously by Al-Najjar (2011) and by Magd and Nabulsi (2012) but was not observed with significant relevance in this study. On the other hand, difficulties related with the misunderstanding of the standard and the bureaucratization that it causes were difficulties faced by the most part of the organizations of the present study and they are in line with the findings of the previous empirical studies (see Zeng et al., 2007; Boiral, 2011; Magd and Nabulsi, 2012).

The findings also revealed the main checked motivation for the ISO 14001 implementation was the improvement of the environmental performance, which meets the main reason of existence of this standard and has been a topic increasingly underlined (Zhao et al., 2006; ISO, 2016). Regarding this topic, although many researches have focused on the ability of ISO 14001 to generate a positive effect on performance, they have found contrasting evidences (Testa et al., 2014). Furthermore, the main benefits observed in the surveyed enterprises concerning the adoption of this management system were the following: improvement in organizational culture, better management and control of industrial waste, improvement of the corporate image and waste reduction.

Regarding the main difficulties faced in the ISO 14001 implementation process, were verified, although in small proportions,

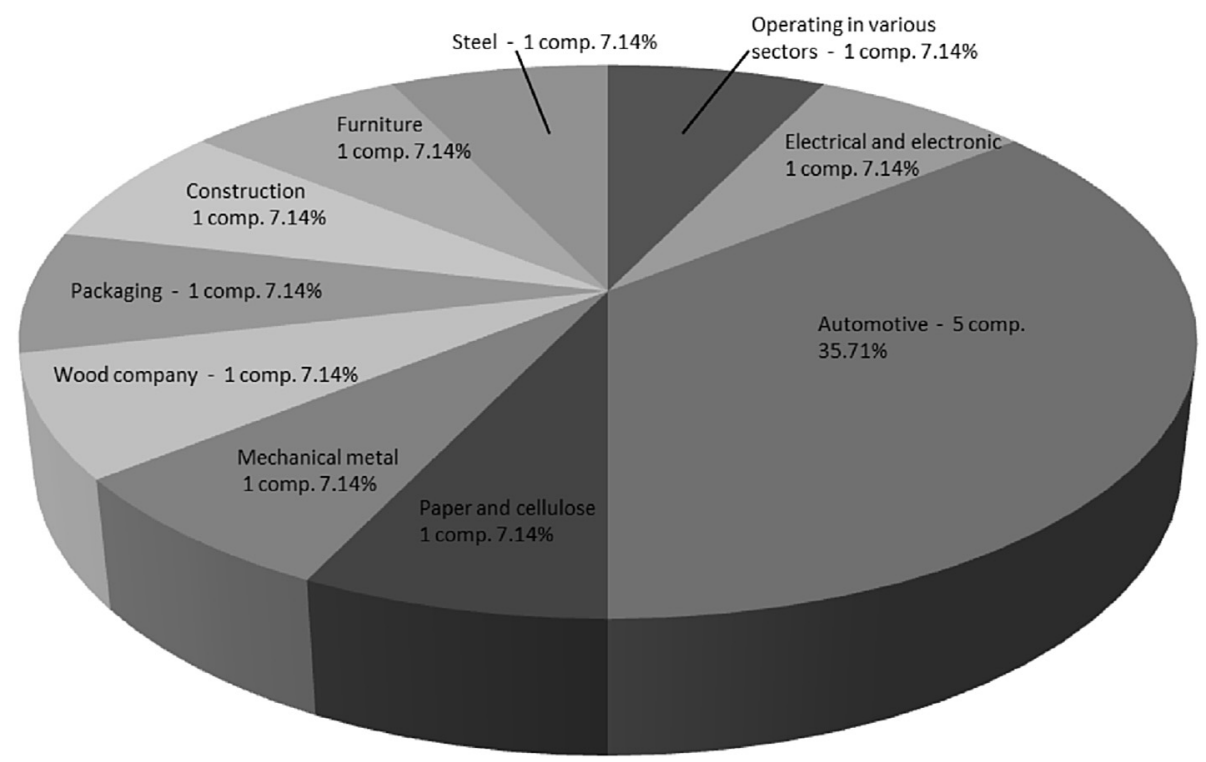

Fig. 2. Distribution of companies by sector. 
Table 1

Main features of QMS ISO 9001 in the studied companies.

\begin{tabular}{|c|c|c|c|c|c|c|c|c|c|c|c|c|c|c|c|c|}
\hline \multirow[t]{2}{*}{ Questions directed at } & \multicolumn{2}{|l|}{ ISO 9001} & \multirow{2}{*}{$\frac{A}{1993}$} & \multirow{2}{*}{$\frac{B}{1999}$} & \multirow{2}{*}{$\frac{C}{2004}$} & \multirow{2}{*}{$\frac{\mathrm{D}}{1996}$} & \multirow{2}{*}{$\frac{E}{2003}$} & \multirow{2}{*}{$\frac{F}{1997}$} & \multirow{2}{*}{$\frac{G}{2006}$} & \multirow{2}{*}{$\frac{\mathrm{H}}{1992}$} & \multirow{2}{*}{$\frac{I}{1994}$} & \multirow{2}{*}{$\frac{\mathrm{J}}{1994}$} & \multirow{2}{*}{$\frac{K}{1994}$} & \multirow{2}{*}{$\frac{L}{2003}$} & \multirow{2}{*}{$\frac{M}{2000}$} & \multirow{2}{*}{$\frac{\mathrm{N}}{1995}$} \\
\hline & Year 1st. certification & & & & & & & & & & & & & & & \\
\hline Top Management & \multicolumn{2}{|c|}{ Certification 2008 version } & & $\checkmark$ & $\checkmark$ & $\checkmark$ & $\checkmark$ & $\checkmark$ & $\checkmark$ & $\checkmark$ & $\checkmark$ & $\checkmark$ & $\checkmark$ & $\checkmark$ & $\checkmark$ & $\checkmark$ \\
\hline \multirow[t]{6}{*}{ Representative } & $\begin{array}{l}\text { Simultaneous } \\
\text { implementation with } \\
\text { another system }\end{array}$ & $\begin{array}{l}\text { ISO } 14001 \\
\text { OHSAS } 18001\end{array}$ & & & & & & & & & & & & & & \\
\hline & \multirow{5}{*}{$\begin{array}{l}\text { Main motivations for } \\
\text { certification }\end{array}$} & Competing Pressures & & & & $\checkmark$ & $\checkmark$ & & & $\checkmark$ & & $\checkmark$ & & & $\checkmark$ & $\checkmark$ \\
\hline & & Customer Pressures & & $\checkmark$ & & $\checkmark$ & $\checkmark$ & & & & $\checkmark$ & $\checkmark$ & & & $\checkmark$ & $\checkmark$ \\
\hline & & $\begin{array}{l}\text { Self-evaluation of the } \\
\text { company }\end{array}$ & & $\checkmark$ & $\checkmark$ & $\checkmark$ & & $\checkmark$ & $\checkmark$ & $\checkmark$ & & $\checkmark$ & $\checkmark$ & $\checkmark$ & $\checkmark$ & $\checkmark$ \\
\hline & & $\begin{array}{l}\text { Requirement of any } \\
\text { economic bloc or foreign } \\
\text { government }\end{array}$ & & & & & & & & & & $\checkmark$ & & & & $\checkmark$ \\
\hline & & Marketing strategy & $\checkmark$ & $\checkmark$ & & $\checkmark$ & $\checkmark$ & & $\checkmark$ & $\checkmark$ & $\checkmark$ & $\checkmark$ & & & & $\checkmark$ \\
\hline \multirow{13}{*}{$\begin{array}{l}\text { Top Management } \\
\text { Representative, Production } \\
\text { Managers and Key employees }\end{array}$} & \multirow{13}{*}{$\begin{array}{l}\text { Main benefits with the } \\
\text { implementation of ISO } \\
9001\end{array}$} & $\begin{array}{l}\text { Improvement in the } \\
\text { organizational culture }\end{array}$ & $\checkmark$ & $\checkmark$ & $\checkmark$ & $\checkmark$ & $\checkmark$ & $\checkmark$ & $\checkmark$ & $\checkmark$ & $\checkmark$ & $\checkmark$ & $\checkmark$ & $\checkmark$ & $\checkmark$ & $\checkmark$ \\
\hline & & $\begin{array}{l}\text { Increase in the company's } \\
\text { revenues }\end{array}$ & & $\checkmark$ & & & & $\checkmark$ & $\checkmark$ & $\checkmark$ & & $\checkmark$ & & & $\checkmark$ & $\checkmark$ \\
\hline & & $\begin{array}{l}\text { Improvement efficiency of } \\
\text { internal operations }\end{array}$ & & $\checkmark$ & & & $\checkmark$ & $\checkmark$ & $\checkmark$ & $\checkmark$ & $\checkmark$ & $\checkmark$ & $\checkmark$ & $\checkmark$ & $\checkmark$ & $\checkmark$ \\
\hline & & $\begin{array}{l}\text { Improvement company } \\
\text { image }\end{array}$ & $\checkmark$ & $\checkmark$ & & $\checkmark$ & $\checkmark$ & $\checkmark$ & $\checkmark$ & $\checkmark$ & $\checkmark$ & $\checkmark$ & $\checkmark$ & & $\checkmark$ & $\checkmark$ \\
\hline & & $\begin{array}{l}\text { Improvement the quality } \\
\text { of process }\end{array}$ & $\checkmark$ & $\checkmark$ & & & $\checkmark$ & $\checkmark$ & $\checkmark$ & $\checkmark$ & $\checkmark$ & $\checkmark$ & $\checkmark$ & $\checkmark$ & $\checkmark$ & $\checkmark$ \\
\hline & & $\begin{array}{l}\text { Improvement in the } \\
\text { internal communication }\end{array}$ & $\checkmark$ & $\checkmark$ & & & $\checkmark$ & $\checkmark$ & $\checkmark$ & $\checkmark$ & $\checkmark$ & $\checkmark$ & $\checkmark$ & $\checkmark$ & $\checkmark$ & $\checkmark$ \\
\hline & & $\begin{array}{l}\text { Improvement in the } \\
\text { customer relations }\end{array}$ & $\checkmark$ & $\checkmark$ & & $\checkmark$ & $\checkmark$ & $\checkmark$ & $\checkmark$ & $\checkmark$ & $\checkmark$ & $\checkmark$ & $\checkmark$ & $\checkmark$ & & $\checkmark$ \\
\hline & & $\begin{array}{l}\text { Reduction of waste during } \\
\text { the process }\end{array}$ & & $\checkmark$ & & & $\checkmark$ & $\checkmark$ & $\checkmark$ & $\checkmark$ & $\checkmark$ & $\checkmark$ & & $\checkmark$ & $\checkmark$ & $\checkmark$ \\
\hline & & $\begin{array}{l}\text { Increased customer } \\
\text { retention }\end{array}$ & $\checkmark$ & $\checkmark$ & & $\checkmark$ & $\checkmark$ & & $\checkmark$ & $\checkmark$ & & $\checkmark$ & & & & $\checkmark$ \\
\hline & & Increasing productivity & & $\checkmark$ & & & $\checkmark$ & $\checkmark$ & $\checkmark$ & $\checkmark$ & & $\checkmark$ & & & & $\checkmark$ \\
\hline & & $\begin{array}{l}\text { Savings in the purchase of } \\
\text { raw materials }\end{array}$ & & $\checkmark$ & & & $\checkmark$ & & $\checkmark$ & $\checkmark$ & & & & & $\checkmark$ & $\checkmark$ \\
\hline & & $\begin{array}{l}\text { Greater visibility of the } \\
\text { company with customers } \\
\text { and suppliers }\end{array}$ & $\checkmark$ & $\checkmark$ & & $\checkmark$ & $\checkmark$ & $\checkmark$ & & $\checkmark$ & & & & $\checkmark$ & $\checkmark$ & $\checkmark$ \\
\hline & & Greater process control & & $\checkmark$ & & $\checkmark$ & & $\checkmark$ & & $\checkmark$ & & $\checkmark$ & & $\checkmark$ & $\checkmark$ & $\checkmark$ \\
\hline \multirow{6}{*}{$\begin{array}{l}\text { Top Management } \\
\text { Representative and } \\
\text { Production Managers }\end{array}$} & \multirow{6}{*}{$\begin{array}{l}\text { Main difficulties with } \\
\text { the implementation of } \\
\text { ISO } 9001\end{array}$} & Resistance from employees & & & & & $\checkmark$ & & & $\checkmark$ & & & & & & \\
\hline & & Low-skilled workforce & & & & & & & & & & & & $\checkmark$ & & \\
\hline & & High implementation costs & $\checkmark$ & & & & $\checkmark$ & & & & & & $\checkmark$ & & & \\
\hline & & $\begin{array}{l}\text { Difficulty in understanding } \\
\text { the standard }\end{array}$ & & & $\checkmark$ & $\checkmark$ & & $\checkmark$ & $\checkmark$ & & & & & & & \\
\hline & & Time longer than expected & & $\checkmark$ & & & $\checkmark$ & & & & & & & & & \\
\hline & & $\begin{array}{l}\text { Excessive } \\
\text { bureaucratization }\end{array}$ & $\checkmark$ & & $\checkmark$ & & $\checkmark$ & & & & $\checkmark$ & & & $\checkmark$ & & $\checkmark$ \\
\hline
\end{tabular}

the high implementation costs and the excessive bureaucratization The fact that $57.14 \%$ of the companies (i.e., eight of them) have implemented both ISO 14001 and OHSAS 18001 simultaneously is also significant.

Moreover, only $14.35 \%$ of the analyzed companies (i.e., C and G) were certified by ISO 14001 EMS before the ISO 9001 QMS. As there is compatibility between the standards, they can be implemented in any order or sequence, even simultaneously, in an integrated way or not (Karapetrovic and Casadesús, 2009). However, the standardization of QMS first is the most common framework (Karapetrovic and Casadesús, 2009; Santos et al., 2013). This fact has been reported by the theory that highlights it occurs due to the market's pressure; the greater ease in meet the requirements, etc (Karapetrovic and Casadesús, 2009).

Regarding the characteristics of the OHSAS 18001 OHSMS, all the companies obtained their first certification in 2007. This fact ratifies other scientific studies (e.g. Santos et al., 2013), which indicates that among the three standards OHSAS 18001 is usually implemented lastly or at the same time as a second one. This fact simplifies the implementation process, enabling subsequently the system to be implemented with lower time and costs than the previous ones, due to the existence of culture and the necessary instruments for the proper development of standardization, such as training, evaluation and continuous improvement of processes.

Table 4 shows the features of the integration of management systems in the companies studied.

As shown in Table 4, the companies integrated their management systems with different intensities. Regardless of it, all of them were motivated by a self-reflection concerning the strategic and operational situation (self-evaluation of the company), in such a way to make the best of the synergy between them, reducing costs in its management and increasing competitiveness. The importance of company's self-evaluation was also observed by Oliveira (2013), who highlighted the importance of customized integration to the companies' reality, after all, when it is done the integration process generates less resistance and presents efficiency in using the available resources.

Regarding the integration benefits identified in the companies studied, the followings were observed: improvement in the efficiency of operations and internal communication, greater agility in the decision-making process, increase in the quality of goods and services produced or provided and increase in the reliability of the 
Table 2

Main features of EMS ISO 14001 in the studied companies.

\begin{tabular}{|c|c|c|c|c|c|c|c|c|c|c|c|c|c|c|c|c|}
\hline \multirow[t]{2}{*}{ Questions directed at } & \multicolumn{2}{|l|}{ ISO 14001} & \multirow{2}{*}{$\frac{A}{2001}$} & \multirow{2}{*}{$\frac{B}{2003}$} & \multirow{2}{*}{$\frac{C}{1999}$} & \multirow{2}{*}{$\frac{D}{2000}$} & \multirow{2}{*}{$\frac{E}{2005}$} & \multirow{2}{*}{$\frac{F}{2003}$} & \multirow{2}{*}{$\frac{G}{2003}$} & \multirow{2}{*}{$\frac{\mathrm{H}}{2002}$} & \multirow{2}{*}{$\frac{\mathrm{I}}{2000}$} & \multirow{2}{*}{$\frac{\mathrm{J}}{2003}$} & \multirow{2}{*}{$\frac{K}{2008}$} & \multirow{2}{*}{$\frac{\mathrm{L}}{2005}$} & \multirow{2}{*}{$\frac{M}{2002}$} & \multirow{2}{*}{$\frac{N}{2004}$} \\
\hline & Year 1st. certification & & & & & & & & & & & & & & & \\
\hline \multirow{9}{*}{$\begin{array}{l}\text { Top Management } \\
\text { Representative }\end{array}$} & \multicolumn{2}{|c|}{ Certification 2004 version } & & $\checkmark$ & $\checkmark$ & $\checkmark$ & $\checkmark$ & $\checkmark$ & $\checkmark$ & $\checkmark$ & $\checkmark$ & $\checkmark$ & $\checkmark$ & $\checkmark$ & $\checkmark$ & $\checkmark$ \\
\hline & Simultaneous & ISO 9001 & & & & & & & & & & & & & & \\
\hline & $\begin{array}{l}\text { implementation with } \\
\text { another system }\end{array}$ & OHSAS 18001 & $\checkmark$ & $\checkmark$ & & & $\checkmark$ & $\checkmark$ & $\checkmark$ & & & $\checkmark$ & $\checkmark$ & $\checkmark$ & & \\
\hline & Main motivations for & Competing Pressures & $\checkmark$ & $\checkmark$ & & & $\checkmark$ & & & & & & & & & $\checkmark$ \\
\hline & certification & Customer Pressures & $\checkmark$ & $\checkmark$ & & $\checkmark$ & $\checkmark$ & & & & & & & & & $\checkmark$ \\
\hline & & Self-evaluation of the company & $\checkmark$ & $\checkmark$ & $\checkmark$ & $\checkmark$ & & $\checkmark$ & $\checkmark$ & & & $\checkmark$ & $\checkmark$ & $\checkmark$ & $\checkmark$ & $\checkmark$ \\
\hline & & $\begin{array}{l}\text { Requirement of any economic } \\
\text { bloc or foreign government }\end{array}$ & & $\checkmark$ & & & & & & $\checkmark$ & & & & & & $\checkmark$ \\
\hline & & Marketing strategy & $\checkmark$ & $\checkmark$ & & $\checkmark$ & $\checkmark$ & & $\checkmark$ & $\checkmark$ & & & & & $\checkmark$ & $\checkmark$ \\
\hline & & $\begin{array}{l}\text { Improving the environmental } \\
\text { performance }\end{array}$ & $\checkmark$ & $\checkmark$ & $\checkmark$ & $\checkmark$ & $\checkmark$ & $\checkmark$ & $\checkmark$ & & $\checkmark$ & $\checkmark$ & $\checkmark$ & $\checkmark$ & $\checkmark$ & $\checkmark$ \\
\hline \multirow{12}{*}{$\begin{array}{l}\text { Top Management } \\
\text { Representative, Production } \\
\text { Managers and Key } \\
\text { employees }\end{array}$} & \multirow{12}{*}{$\begin{array}{l}\text { Main benefits with } \\
\text { the implementation } \\
\text { of ISO } 14001\end{array}$} & $\begin{array}{l}\text { Improvement in the } \\
\text { organizational culture }\end{array}$ & $\checkmark$ & $\checkmark$ & $\checkmark$ & $\checkmark$ & $\checkmark$ & $\checkmark$ & $\checkmark$ & $\checkmark$ & $\checkmark$ & $\checkmark$ & $\checkmark$ & $\checkmark$ & $\checkmark$ & $\checkmark$ \\
\hline & & $\begin{array}{l}\text { Improvement efficiency of } \\
\text { internal operations }\end{array}$ & & $\checkmark$ & & $\checkmark$ & $\checkmark$ & $\checkmark$ & $\checkmark$ & & $\checkmark$ & $\checkmark$ & & $\checkmark$ & $\checkmark$ & $\checkmark$ \\
\hline & & Improvement company image & $\checkmark$ & $\checkmark$ & & $\checkmark$ & $\checkmark$ & $\checkmark$ & $\checkmark$ & $\checkmark$ & $\checkmark$ & $\checkmark$ & $\checkmark$ & $\checkmark$ & $\checkmark$ & $\checkmark$ \\
\hline & & $\begin{array}{l}\text { Improvement in the internal } \\
\text { communication }\end{array}$ & & $\checkmark$ & $\checkmark$ & $\checkmark$ & $\checkmark$ & $\checkmark$ & $\checkmark$ & $\checkmark$ & & & $\checkmark$ & $\checkmark$ & $\checkmark$ & $\checkmark$ \\
\hline & & $\begin{array}{l}\text { Improvement in the customer } \\
\text { relations }\end{array}$ & & $\checkmark$ & & $\checkmark$ & $\checkmark$ & $\checkmark$ & $\checkmark$ & & & $\checkmark$ & $\checkmark$ & $\checkmark$ & $\checkmark$ & $\checkmark$ \\
\hline & & $\begin{array}{l}\text { Reduction of waste during the } \\
\text { process }\end{array}$ & $\checkmark$ & $\checkmark$ & $\checkmark$ & $\checkmark$ & $\checkmark$ & $\checkmark$ & $\checkmark$ & & $\checkmark$ & $\checkmark$ & $\checkmark$ & $\checkmark$ & $\checkmark$ & $\checkmark$ \\
\hline & & Increased customer retention & & $\checkmark$ & & $\checkmark$ & $\checkmark$ & & $\checkmark$ & & $\checkmark$ & $\checkmark$ & $\checkmark$ & & & $\checkmark$ \\
\hline & & Increasing productivity & & $\checkmark$ & & $\checkmark$ & $\checkmark$ & & $\checkmark$ & & & & & & $\checkmark$ & $\checkmark$ \\
\hline & & $\begin{array}{l}\text { Better management and } \\
\text { control of environmental } \\
\text { aspects and industrial waste }\end{array}$ & $\checkmark$ & $\checkmark$ & $\checkmark$ & $\checkmark$ & $\checkmark$ & $\checkmark$ & $\checkmark$ & $\checkmark$ & $\checkmark$ & $\checkmark$ & $\checkmark$ & $\checkmark$ & $\checkmark$ & $\checkmark$ \\
\hline & & Greater process control & & $\checkmark$ & $\checkmark$ & $\checkmark$ & $\checkmark$ & $\checkmark$ & $\checkmark$ & $\checkmark$ & & $\checkmark$ & & $\checkmark$ & $\checkmark$ & $\checkmark$ \\
\hline & & Easier decision-making & & $\checkmark$ & & $\checkmark$ & $\checkmark$ & $\checkmark$ & $\checkmark$ & & & & $\checkmark$ & $\checkmark$ & & $\checkmark$ \\
\hline & & $\begin{array}{l}\text { Reduction of fines and } \\
\text { environmental }\end{array}$ & $\checkmark$ & $\checkmark$ & & & $\checkmark$ & $\checkmark$ & $\checkmark$ & & & & $\checkmark$ & $\checkmark$ & $\checkmark$ & $\checkmark$ \\
\hline \multirow{6}{*}{$\begin{array}{l}\text { Top Management } \\
\text { Representative and } \\
\text { Production Managers }\end{array}$} & \multirow{6}{*}{$\begin{array}{l}\text { Main difficulties with } \\
\text { the implementation } \\
\text { of ISO } 14001\end{array}$} & Resistance from employees & & & & & $\checkmark$ & & & & & & & & & \\
\hline & & Low-skilled workforce & $\checkmark$ & & & & & & & $\checkmark$ & & & & $\checkmark$ & & \\
\hline & & High implementation costs & $\checkmark$ & & & & $\checkmark$ & & & $\checkmark$ & & & $\checkmark$ & $\checkmark$ & & \\
\hline & & $\begin{array}{l}\text { Difficulty in understanding the } \\
\text { standard }\end{array}$ & $\checkmark$ & & & $\checkmark$ & & & $\checkmark$ & & & & & $\checkmark$ & & \\
\hline & & Time longer than expected & & $\checkmark$ & & & $\checkmark$ & & & $\checkmark$ & & & & & & \\
\hline & & Excessive bureaucratization & & & & & $\checkmark$ & & $\checkmark$ & $\checkmark$ & & & & $\checkmark$ & & $\checkmark$ \\
\hline
\end{tabular}

products and processes. These findings corroborate with previous studies of Karapetrovic and Casadesús (2009), Santos et al. (2013), Oliveira (2013) and Bernardo et al. (2015).

The findings showed that the benefits least checked regarding integration were the following: improved customer retention, flexibility gain, lead time reduction and final cost reduction of products. The low incidence of benefits such as increased customer retention, at least at first sight, can cause some awkwardness. When firms were asked about it, they argued that integration does not retain customers, but only improve the quality of products and process.

In most of the companies the three management systems were implemented in different periods, being guided by different consulting firms. This characteristic makes of the full integration a very complex process, which demands a high amount of human and financial resources to be achieved. This complexity is the main difficulty faced by the companies during the integration process and can be overcome with the elaboration of a well-developed integration plan, in which the elements of all management systems are described from an integrated perspective, as for example, description of activities, their anticipated duration, the resources necessary for their execution, the individuals responsible for them, etc. This holistic management is important to organize and promote an effective IMS.

Further, to overcome difficulties related to high amount of human resources, it is suggested to organize an integration team with representatives from the main sectors of the company to act as multipliers of the integration techniques. Regarding financial resources, it should be highlighted that despite of many studies have concluded that integration of MSs promotes cost savings (see e.g. Naveh and Marcus, 2004; Salomone, 2008); there is a lack of scientific studies comparing implementation costs and costs saved with implementation. In this sense, it is suggested for future studies to explore this relationship from a long-term perspective.

Once identified the motivations and another key features regarding the integration process in the companies studied; the procedures, elements and integrable functions in each one of them were analyzed.

Table 5 summarizes the procedures, elements and integrable functions in the fourteen companies studied.

As can be seen in Table 5, 64.29\% of the companies (i.e., nine of them) have integrated their manuals, policies, objectives and goals concerning the three systems. These companies have created an IMS manual that comprises not only quality elements, environment and occupational health and safety, singly, but that comprises all the integrated elements. In this sense, Oliveira (2013) argued that the decision to formally integrate the systems practically determines the need for a manual that covers the elements MSs integration. In line with the decision of integrate the systems and develop a single integrated manual, the integration of policies, objectives and targets for the three systems in these companies were also observed. 
Table 3

Main features of OHSMS OHSAS 18001 in the studied companies.

\begin{tabular}{|c|c|c|c|c|c|c|c|c|c|c|c|c|c|c|c|c|}
\hline \multirow[t]{2}{*}{ Questions directed at } & \multicolumn{2}{|l|}{ OHSAS 18001} & \multirow{2}{*}{$\frac{A}{2001}$} & \multirow{2}{*}{$\frac{B}{2003}$} & \multirow{2}{*}{$\frac{C}{2001}$} & \multirow{2}{*}{$\frac{D}{2005}$} & \multirow{2}{*}{$\frac{E}{2005}$} & \multirow{2}{*}{$\frac{F}{2003}$} & \multirow{2}{*}{$\frac{G}{2003}$} & \multirow{2}{*}{$\frac{\mathrm{H}}{2007}$} & \multirow{2}{*}{$\frac{I}{2008}$} & \multirow{2}{*}{$\frac{J}{2003}$} & \multirow{2}{*}{$\frac{K}{2008}$} & \multirow{2}{*}{$\frac{\mathrm{L}}{2005}$} & \multirow{2}{*}{$\frac{M}{2003}$} & \multirow{2}{*}{$\frac{N}{2007}$} \\
\hline & Year 1st. certification & & & & & & & & & & & & & & & \\
\hline \multirow{8}{*}{$\begin{array}{l}\text { Top Management } \\
\text { Representative }\end{array}$} & \multicolumn{2}{|l|}{ Certification 2007 version } & & $\checkmark$ & $\checkmark$ & $\checkmark$ & $\checkmark$ & $\checkmark$ & $\checkmark$ & $\checkmark$ & $\checkmark$ & $\checkmark$ & $\checkmark$ & $\checkmark$ & $\checkmark$ & $\checkmark$ \\
\hline & Simultaneous & ISO 9001 & & & & & & & & & & & & & & \\
\hline & $\begin{array}{l}\text { implementation with } \\
\text { another system }\end{array}$ & ISO 14001 & $\checkmark$ & $\checkmark$ & & & $\checkmark$ & $\checkmark$ & $\checkmark$ & & & $\checkmark$ & $\checkmark$ & $\checkmark$ & & \\
\hline & Main motivations for & Competing Pressures & & $\checkmark$ & & & & & & & & & & & & $\checkmark$ \\
\hline & certification & Customer Pressures & & $\checkmark$ & & $\checkmark$ & & & & & & & & & & $\checkmark$ \\
\hline & & $\begin{array}{l}\text { Self-evaluation of the } \\
\text { company }\end{array}$ & $\checkmark$ & $\checkmark$ & $\checkmark$ & $\checkmark$ & $\checkmark$ & $\checkmark$ & $\checkmark$ & $\checkmark$ & $\checkmark$ & $\checkmark$ & $\checkmark$ & $\checkmark$ & $\checkmark$ & $\checkmark$ \\
\hline & & Marketing strategy & $\checkmark$ & $\checkmark$ & & & $\checkmark$ & & $\checkmark$ & $\checkmark$ & & & & & $\checkmark$ & $\checkmark$ \\
\hline & & $\begin{array}{l}\text { Improving the } \\
\text { performance of health and } \\
\text { safety }\end{array}$ & $\checkmark$ & $\checkmark$ & $\checkmark$ & & $\checkmark$ & $\checkmark$ & $\checkmark$ & $\checkmark$ & & $\checkmark$ & $\checkmark$ & $\checkmark$ & $\checkmark$ & $\checkmark$ \\
\hline \multirow{14}{*}{$\begin{array}{l}\text { Top Management } \\
\text { Representative, Production } \\
\text { Managers and Key } \\
\text { employees }\end{array}$} & $\begin{array}{l}\text { Main benefits with the } \\
\text { implementation of }\end{array}$ & $\begin{array}{l}\text { Improvement in the } \\
\text { organizational culture }\end{array}$ & $\checkmark$ & $\checkmark$ & $\checkmark$ & $\checkmark$ & $\checkmark$ & $\checkmark$ & $\checkmark$ & $\checkmark$ & $\checkmark$ & $\checkmark$ & $\checkmark$ & & $\checkmark$ & $\checkmark$ \\
\hline & OHSAS 18001 & $\begin{array}{l}\text { Reduction of occupational } \\
\text { accidents }\end{array}$ & $\checkmark$ & $\checkmark$ & $\checkmark$ & $\checkmark$ & $\checkmark$ & $\checkmark$ & $\checkmark$ & $\checkmark$ & $\checkmark$ & $\checkmark$ & $\checkmark$ & $\checkmark$ & $\checkmark$ & $\checkmark$ \\
\hline & & $\begin{array}{l}\text { Reduction of occupational } \\
\text { diseases }\end{array}$ & $\checkmark$ & $\checkmark$ & & $\checkmark$ & $\checkmark$ & $\checkmark$ & $\checkmark$ & $\checkmark$ & $\checkmark$ & $\checkmark$ & $\checkmark$ & $\checkmark$ & $\checkmark$ & $\checkmark$ \\
\hline & & $\begin{array}{l}\text { Reduction clearance times } \\
\text { for diseases }\end{array}$ & & $\checkmark$ & & $\checkmark$ & $\checkmark$ & $\checkmark$ & $\checkmark$ & & $\checkmark$ & $\checkmark$ & $\checkmark$ & $\checkmark$ & $\checkmark$ & $\checkmark$ \\
\hline & & $\begin{array}{l}\text { Improvement efficiency of } \\
\text { internal operations }\end{array}$ & & $\checkmark$ & $\checkmark$ & & $\checkmark$ & & $\checkmark$ & $\checkmark$ & & $\checkmark$ & $\checkmark$ & $\checkmark$ & $\checkmark$ & $\checkmark$ \\
\hline & & $\begin{array}{l}\text { Improvement company } \\
\text { image }\end{array}$ & $\checkmark$ & $\checkmark$ & $\checkmark$ & $\checkmark$ & $\checkmark$ & $\checkmark$ & $\checkmark$ & $\checkmark$ & & $\checkmark$ & $\checkmark$ & $\checkmark$ & $\checkmark$ & $\checkmark$ \\
\hline & & $\begin{array}{l}\text { Improvement the quality of } \\
\text { process }\end{array}$ & & $\checkmark$ & $\checkmark$ & & $\checkmark$ & $\checkmark$ & $\checkmark$ & $\checkmark$ & & & $\checkmark$ & & $\checkmark$ & $\checkmark$ \\
\hline & & $\begin{array}{l}\text { Improvement in the } \\
\text { internal communication }\end{array}$ & & $\checkmark$ & $\checkmark$ & & $\checkmark$ & & $\checkmark$ & $\checkmark$ & & & $\checkmark$ & $\checkmark$ & $\checkmark$ & $\checkmark$ \\
\hline & & $\begin{array}{l}\text { Increased customer } \\
\text { retention }\end{array}$ & $\checkmark$ & & $\checkmark$ & $\checkmark$ & $\checkmark$ & $\checkmark$ & $\checkmark$ & $\checkmark$ & & & $\checkmark$ & $\checkmark$ & $\checkmark$ & $\checkmark$ \\
\hline & & $\begin{array}{l}\text { Reduction of waste during } \\
\text { the process }\end{array}$ & & $\checkmark$ & $\checkmark$ & & $\checkmark$ & & $\checkmark$ & $\checkmark$ & & $\checkmark$ & $\checkmark$ & & $\checkmark$ & $\checkmark$ \\
\hline & & $\begin{array}{l}\text { Increasing visibility of the } \\
\text { company with customers } \\
\text { and suppliers }\end{array}$ & $\checkmark$ & & $\checkmark$ & $\checkmark$ & $\checkmark$ & $\checkmark$ & $\checkmark$ & & & & & & $\checkmark$ & $\checkmark$ \\
\hline & & Greater process control & & $\checkmark$ & $\checkmark$ & $\checkmark$ & $\checkmark$ & & $\checkmark$ & $\checkmark$ & & & & $\checkmark$ & $\checkmark$ & $\checkmark$ \\
\hline & & Easier decision-making & & & $\checkmark$ & $\checkmark$ & $\checkmark$ & $\checkmark$ & $\checkmark$ & $\checkmark$ & & & $\checkmark$ & $\checkmark$ & & $\checkmark$ \\
\hline & & $\begin{array}{l}\text { Risk reduction and } \\
\text { production periods stop }\end{array}$ & $\checkmark$ & $\checkmark$ & $\checkmark$ & $\checkmark$ & $\checkmark$ & $\checkmark$ & $\checkmark$ & & $\checkmark$ & & & $\checkmark$ & $\checkmark$ & $\checkmark$ \\
\hline \multirow{6}{*}{$\begin{array}{l}\text { Top Management } \\
\text { Representative and } \\
\text { Production Managers }\end{array}$} & \multirow{6}{*}{$\begin{array}{l}\text { Main difficulties with } \\
\text { the implementation of } \\
\text { OHSAS } 18001\end{array}$} & Resistance from employees & & & & & $\checkmark$ & $\checkmark$ & & $\checkmark$ & & & & & & $\checkmark$ \\
\hline & & Low-skilled workforce & & & & & & & & $\checkmark$ & & & $\checkmark$ & & & \\
\hline & & High implementation costs & $\checkmark$ & & & & $\checkmark$ & $\checkmark$ & & $\checkmark$ & & $\checkmark$ & $\checkmark$ & & & \\
\hline & & $\begin{array}{l}\text { Difficulty in understanding } \\
\text { the standard }\end{array}$ & & & & & & & $\checkmark$ & & & & $\checkmark$ & & & \\
\hline & & Time longer than expected & & $\checkmark$ & & & $\checkmark$ & & & $\checkmark$ & & & & & & \\
\hline & & $\begin{array}{l}\text { Excessive } \\
\text { bureaucratization }\end{array}$ & & $\checkmark$ & & & & & $\checkmark$ & $\checkmark$ & & & & & & \\
\hline
\end{tabular}

The integrated policy was verified at the form of a single text with macro and guiding character, which covers aspects of the three management systems together. As for the goals and objectives, the companies argued that prefer keep them separated, without involving the three systems together because the integration seems to be a more complex task to be achieved. On the other hand, the companies have emphasized that in some situations the integration is easier to be achieved, such as in the case of the requirements that involve training, infrastructure, customer satisfaction, product design and process, among others.

Regarding internal communication, it was verified that $78.57 \%$ of the companies (i.e., 11 companies) use some elements that cover the all three systems simultaneously, such as murals, signs, graphic display, motivational documents, e-mail communications, etc. It enables saving money and aware the workers that these systems must be managed integrally.

In $92.86 \%$ of the companies (i.e., thirteen of them) a considerable level of integration of the items related to work instructions and control records was verified. In addition, $85.72 \%$ (i.e., twelve companies) have presented the integration of their documents control and "structure and responsibility" and $71.45 \%$ (i.e., ten of them) have integrated their "top management" responsibilities and performance indicators.

On the other hand, only $35.71 \%$ of the companies (five companies) have studied some kind of acquisition and integration regarding the process/requirement acquisition and four companies or $28.57 \%$ regarding treatment of non-conformities, corrective actions and external audit. Moreover, explicit guidelines for new suppliers, prospecting existing supplier classification and recommendations for material quotation and purchase taking into account aspects of the three systems were also verified in the companies. It should be highlighted that although they have an integrated manual, the nonconformities in the companies follow the instructions and different procedures for each certifiable management system.

Taking into account the consideration of Oliveira (2013), who alerts that "is advisable to verify the existence of systems, programs and tools that have a commonality with certifiable management 
Table 4

Main features of the integration of management systems.

\begin{tabular}{|c|c|c|c|c|c|c|c|c|c|c|c|c|c|c|c|c|}
\hline Questions directed at & Features of integration of $\mathrm{r}$ & nanagement systems & A & B & $\mathrm{C}$ & $\mathrm{D}$ & $\mathrm{E}$ & $\mathrm{F}$ & G & $\mathrm{H}$ & I & $\mathrm{J}$ & K & $\mathrm{L}$ & M & $\mathrm{N}$ \\
\hline \multirow[t]{7}{*}{ Top Management Representative } & \multirow{7}{*}{$\begin{array}{l}\text { Main motivations for the } \\
\text { integration }\end{array}$} & Competing Pressures & & & $\checkmark$ & & & $\checkmark$ & $\checkmark$ & $\checkmark$ & & & & $\checkmark$ & & \\
\hline & & Customer Pressures & & & $\checkmark$ & & & & & & $\checkmark$ & & & & & $\checkmark$ \\
\hline & & Self-evaluation of the company & $\checkmark$ & $\checkmark$ & $\checkmark$ & $\checkmark$ & $\checkmark$ & $\checkmark$ & $\checkmark$ & $\checkmark$ & $\checkmark$ & $\checkmark$ & $\checkmark$ & $\checkmark$ & $\checkmark$ & $\checkmark$ \\
\hline & & Harnessing the synergy of systems & $\checkmark$ & $\checkmark$ & $\checkmark$ & $\checkmark$ & $\checkmark$ & $\checkmark$ & $\checkmark$ & $\checkmark$ & $\checkmark$ & $\checkmark$ & $\checkmark$ & $\checkmark$ & $\checkmark$ & $\checkmark$ \\
\hline & & Cost reduction in systems management & $\checkmark$ & $\checkmark$ & $\checkmark$ & $\checkmark$ & $\checkmark$ & $\checkmark$ & $\checkmark$ & $\checkmark$ & $\checkmark$ & $\checkmark$ & $\checkmark$ & $\checkmark$ & $\checkmark$ & $\checkmark$ \\
\hline & & Marketing strategy & $\checkmark$ & $\checkmark$ & $\checkmark$ & & & & & & & & $\checkmark$ & & & \\
\hline & & Increasing competitiveness & $\checkmark$ & $\checkmark$ & $\checkmark$ & $\checkmark$ & $\checkmark$ & $\checkmark$ & $\checkmark$ & $\checkmark$ & $\checkmark$ & $\checkmark$ & $\checkmark$ & $\checkmark$ & $\checkmark$ & $\checkmark$ \\
\hline \multirow{12}{*}{$\begin{array}{l}\text { Top Management Representative, } \\
\text { Production Managers } \\
\text { and Key employees }\end{array}$} & \multirow{12}{*}{$\begin{array}{l}\text { Main benefits with } \\
\text { the integration }\end{array}$} & Increase in the company's revenues & $\checkmark$ & $\checkmark$ & $\checkmark$ & & & $\checkmark$ & & & $\checkmark$ & $\checkmark$ & $\checkmark$ & & $\checkmark$ & $\checkmark$ \\
\hline & & $\begin{array}{l}\text { Improvement efficiency of internal operations } \\
\text { Improvement company image }\end{array}$ & $\checkmark$ & $\checkmark$ & $\checkmark$ & $\checkmark$ & $\checkmark$ & $\checkmark$ & $\checkmark$ & $\checkmark$ & $\checkmark$ & $\checkmark$ & $\begin{array}{l}\checkmark \\
\checkmark\end{array}$ & $\begin{array}{l}\checkmark \\
\checkmark\end{array}$ & $\checkmark$ & $\checkmark$ \\
\hline & & Improvement in the internal communication & $\checkmark$ & $\checkmark$ & $\checkmark$ & $\checkmark$ & $\checkmark$ & $\checkmark$ & $\checkmark$ & $\checkmark$ & $\checkmark$ & $\checkmark$ & $\checkmark$ & $\checkmark$ & $\checkmark$ & $\checkmark$ \\
\hline & & Improvement in the customer relations & & $\checkmark$ & $\checkmark$ & $\checkmark$ & $\checkmark$ & $\checkmark$ & & $\checkmark$ & & $\checkmark$ & $\checkmark$ & $\checkmark$ & $\checkmark$ & $\checkmark$ \\
\hline & & Increasing productivity & $\checkmark$ & $\checkmark$ & $\checkmark$ & & & & & & & & $\checkmark$ & & $\checkmark$ & \\
\hline & & $\begin{array}{l}\text { Increased visibility of the company with } \\
\text { customers and suppliers }\end{array}$ & & $\checkmark$ & $\checkmark$ & & & $\checkmark$ & & $\checkmark$ & & & $\checkmark$ & & $\checkmark$ & \\
\hline & & Easier decision-making & $\checkmark$ & $\checkmark$ & $\checkmark$ & $\checkmark$ & $\checkmark$ & $\checkmark$ & $\checkmark$ & $\checkmark$ & $\checkmark$ & $\checkmark$ & $\checkmark$ & $\checkmark$ & $\checkmark$ & $\checkmark$ \\
\hline & & $\begin{array}{l}\text { Increase the quality of goods and } \\
\text { services provided }\end{array}$ & $\checkmark$ & $\checkmark$ & $\checkmark$ & $\checkmark$ & $\checkmark$ & $\checkmark$ & $\checkmark$ & $\checkmark$ & $\checkmark$ & $\checkmark$ & $\checkmark$ & $\checkmark$ & $\checkmark$ & $\checkmark$ \\
\hline & & $\begin{array}{l}\text { Increased product reliability and processes } \\
\text { Reduction of cost of the final product }\end{array}$ & $\checkmark$ & $\checkmark$ & $\checkmark$ & $\checkmark$ & $\checkmark$ & $\checkmark$ & $\checkmark$ & $\checkmark$ & $\checkmark$ & $\checkmark$ & $\begin{array}{l}\checkmark \\
\checkmark\end{array}$ & $\checkmark$ & $\checkmark$ & $\checkmark$ \\
\hline & & $\begin{array}{l}\text { Decreasing in the number of information } \\
\text { and documents }\end{array}$ & $\checkmark$ & $\checkmark$ & $\checkmark$ & $\checkmark$ & $\checkmark$ & $\checkmark$ & $\checkmark$ & $\checkmark$ & $\checkmark$ & $\checkmark$ & $\checkmark$ & $\checkmark$ & $\checkmark$ & $\checkmark$ \\
\hline & & Decreasing the cost of training & $\checkmark$ & $\checkmark$ & $\checkmark$ & $\checkmark$ & & & & $\checkmark$ & $\checkmark$ & $\checkmark$ & $\checkmark$ & $\checkmark$ & $\checkmark$ & $\checkmark$ \\
\hline & & Reduction in audit costs & $\checkmark$ & $\checkmark$ & $\checkmark$ & $\checkmark$ & & & & $\checkmark$ & $\checkmark$ & $\checkmark$ & $\checkmark$ & $\checkmark$ & $\checkmark$ & $\checkmark$ \\
\hline \multirow{8}{*}{$\begin{array}{l}\text { Top Management Representative } \\
\text { and Production Managers }\end{array}$} & \multirow{8}{*}{$\begin{array}{l}\text { Main difficulties with the } \\
\text { integration }\end{array}$} & Resistance from employees & & & & & $\checkmark$ & & & $\checkmark$ & & & & & & \\
\hline & & Low-skilled workforce & & & & & & & & & & & & $\checkmark$ & & \\
\hline & & High implementation costs & $\checkmark$ & $\checkmark$ & & & $\checkmark$ & & & & & & $\checkmark$ & & & \\
\hline & & Difficulty of compatibility among standards & $\checkmark$ & & $\checkmark$ & $\checkmark$ & & $\checkmark$ & $\checkmark$ & & & & & & & \\
\hline & & Time longer than expected & & $\checkmark$ & & & $\checkmark$ & & & & & & $\checkmark$ & & & \\
\hline & & Excessive bureaucratization & & & & & & & & & & & $\checkmark$ & & & \\
\hline & & High complexity of the integration process & $\checkmark$ & $\checkmark$ & $\checkmark$ & & & & & & & & $\checkmark$ & & & $\checkmark$ \\
\hline & & Low return to great human effort and financial & & & & $\checkmark$ & & & & & & & & $\checkmark$ & & \\
\hline
\end{tabular}

Table 5

Integrated procedures.

\begin{tabular}{|c|c|c|c|c|c|c|c|c|c|c|c|c|c|c|c|c|}
\hline Procedures/functions & A & B & $\mathrm{C}$ & $\mathrm{D}$ & $\mathrm{E}$ & $\mathrm{F}$ & G & $\mathrm{H}$ & I & $\mathrm{J}$ & $\mathrm{K}$ & $\mathrm{L}$ & M & $\mathrm{N}$ & $\%$ & Total amount \\
\hline Manuals & $\checkmark$ & $\checkmark$ & $\checkmark$ & $\checkmark$ & & & & $\checkmark$ & $\checkmark$ & $\checkmark$ & $\checkmark$ & & $\checkmark$ & & 64.29 & 9 \\
\hline Policies & $\checkmark$ & $\checkmark$ & $\checkmark$ & $\checkmark$ & & & & $\checkmark$ & $\checkmark$ & $\checkmark$ & $\checkmark$ & & $\checkmark$ & & 64.29 & 9 \\
\hline Objectives and goals & $\checkmark$ & $\checkmark$ & $\checkmark$ & $\checkmark$ & & & & & $\checkmark$ & $\checkmark$ & $\checkmark$ & & $\checkmark$ & & 64.29 & 9 \\
\hline Structure and responsibility & $\checkmark$ & $\checkmark$ & $\checkmark$ & $\checkmark$ & & $\checkmark$ & & & $\checkmark$ & $\checkmark$ & $\checkmark$ & $\checkmark$ & $\checkmark$ & $\checkmark$ & 85.72 & 12 \\
\hline Top Management & $\checkmark$ & $\checkmark$ & & $\checkmark$ & & $\checkmark$ & $\checkmark$ & $\checkmark$ & $\checkmark$ & & $\checkmark$ & & $\checkmark$ & $\checkmark$ & 71.45 & 10 \\
\hline Work instructions & $\checkmark$ & $\checkmark$ & $\checkmark$ & $\checkmark$ & $\checkmark$ & $\checkmark$ & & $\checkmark$ & $\checkmark$ & $\checkmark$ & $\checkmark$ & $\checkmark$ & $\checkmark$ & $\checkmark$ & 92.86 & 13 \\
\hline Documents control & $\checkmark$ & $\checkmark$ & & & $\checkmark$ & $\checkmark$ & $\checkmark$ & $\checkmark$ & $\checkmark$ & & $\checkmark$ & $\checkmark$ & $\checkmark$ & $\checkmark$ & 85.72 & 12 \\
\hline Control of records & $\checkmark$ & $\checkmark$ & & & $\checkmark$ & $\checkmark$ & $\checkmark$ & $\checkmark$ & $\checkmark$ & $\checkmark$ & $\checkmark$ & $\checkmark$ & $\checkmark$ & $\checkmark$ & 92.86 & 13 \\
\hline Training & $\checkmark$ & $\checkmark$ & $\checkmark$ & & & & & $\checkmark$ & & $\checkmark$ & $\checkmark$ & $\checkmark$ & $\checkmark$ & $\checkmark$ & 57.14 & 8 \\
\hline Internal communication & $\checkmark$ & $\checkmark$ & $\checkmark$ & $\checkmark$ & $\checkmark$ & $\checkmark$ & $\checkmark$ & $\checkmark$ & & & $\checkmark$ & & $\checkmark$ & $\checkmark$ & 78.57 & 11 \\
\hline Emergency plans & $\checkmark$ & $\checkmark$ & $\checkmark$ & $\checkmark$ & & & & $\checkmark$ & & & $\checkmark$ & & $\checkmark$ & & 50.00 & 7 \\
\hline Performance indicators & $\checkmark$ & $\checkmark$ & $\checkmark$ & $\checkmark$ & & & & $\checkmark$ & $\checkmark$ & $\checkmark$ & $\checkmark$ & & $\checkmark$ & $\checkmark$ & 71.45 & 10 \\
\hline Acquisition & $\checkmark$ & $\checkmark$ & & & & & & $\checkmark$ & & & $\checkmark$ & & $\checkmark$ & & 35.71 & 5 \\
\hline Treatment of non-conformities & $\checkmark$ & $\checkmark$ & & & & & & & & & $\checkmark$ & & $\checkmark$ & & 28.57 & 4 \\
\hline Equipment control and inspection/measurement test & $\checkmark$ & $\checkmark$ & $\checkmark$ & $\checkmark$ & & & & $\checkmark$ & $\checkmark$ & $\checkmark$ & $\checkmark$ & & $\checkmark$ & & 64.29 & 9 \\
\hline Preventive actions & $\checkmark$ & $\checkmark$ & & & & & & $\checkmark$ & & & $\checkmark$ & & $\checkmark$ & & 35.71 & 5 \\
\hline Corrective actions & $\checkmark$ & $\checkmark$ & & & & & & & & & $\checkmark$ & & $\checkmark$ & & 28.57 & 4 \\
\hline Internal audit & $\checkmark$ & $\checkmark$ & & $\checkmark$ & & & & $\checkmark$ & & $\checkmark$ & $\checkmark$ & $\checkmark$ & $\checkmark$ & & 57.14 & 8 \\
\hline External audit & $\checkmark$ & $\checkmark$ & & & & & & & & & $\checkmark$ & & $\checkmark$ & & 28.57 & 4 \\
\hline Management review & $\checkmark$ & $\checkmark$ & $\checkmark$ & $\checkmark$ & & & & $\checkmark$ & $\checkmark$ & $\checkmark$ & $\checkmark$ & $\checkmark$ & $\checkmark$ & $\checkmark$ & 78.57 & 11 \\
\hline
\end{tabular}

systems (Balanced Score Card, Six Sigma, Cleaner Production, etc.) to consider their structure and elements as possible enhancers of the integration process", the tools and programs which support an effective way to implement, manage, monitor and improve the organization performance of the three presented systems in the companies studied were also analyzed.

Table 6 presents a compilation of all tools and programs used by the companies studied in alphabetical hierarchical order. The definition of the tools presented in Table 6 can be found in Table 7, if necessary.

As can be seen in Table 6, the brainstorming, the histogram and the Pareto chart are used by all companies and the Ishikawa diagram is used by $92.86 \%$ of them (thirteen companies). It was also observed that these basic tools are used in order to subsidize the development of knowledge and conditions for the use of more complex programs and tools.

$5 \mathrm{~W} 1 \mathrm{H}$ or $5 \mathrm{~W} 2 \mathrm{H}$ (What, When, Where, Who, Why, How and How Much) are adopted in the most companies studied (13 or $92.86 \%$ of them) with the function to structuring their action plans, whether related to quality or not.

In the sequence, the most used tools are benchmarking and FMEA, both used by $85.72 \%$ of the companies ( 12 companies). 
Table 6

Tools and programs used by companies studied.

\begin{tabular}{|c|c|c|c|c|c|c|c|c|c|c|c|c|c|c|c|c|}
\hline & A & $\mathrm{B}$ & $\mathrm{C}$ & $\mathrm{D}$ & $\mathrm{E}$ & $\mathrm{F}$ & G & $\mathrm{H}$ & I & $\mathrm{J}$ & $\mathrm{K}$ & $\mathrm{L}$ & M & $\mathrm{N}$ & $\%$ & Total amount \\
\hline \multicolumn{17}{|l|}{ Tools } \\
\hline $5 \mathrm{~W} 1 \mathrm{H}$ & $\checkmark$ & $\checkmark$ & $\checkmark$ & $\checkmark$ & $\checkmark$ & $\checkmark$ & $\checkmark$ & $\checkmark$ & $\checkmark$ & $\checkmark$ & & $\checkmark$ & $\checkmark$ & $\checkmark$ & 92.86 & 13 \\
\hline Benchmarking & & $\checkmark$ & $\checkmark$ & $\checkmark$ & $\checkmark$ & $\checkmark$ & $\checkmark$ & $\checkmark$ & $\checkmark$ & $\checkmark$ & $\checkmark$ & & $\checkmark$ & $\checkmark$ & 85.72 & 12 \\
\hline Brainstorming & $\checkmark$ & $\checkmark$ & $\checkmark$ & $\checkmark$ & $\checkmark$ & $\checkmark$ & $\checkmark$ & $\checkmark$ & $\checkmark$ & $\checkmark$ & $\checkmark$ & $\checkmark$ & $\checkmark$ & $\checkmark$ & 100 & 14 \\
\hline QCC & & $\checkmark$ & $\checkmark$ & & & & & $\checkmark$ & $\checkmark$ & $\checkmark$ & & $\checkmark$ & $\checkmark$ & $\checkmark$ & 57.14 & 8 \\
\hline SPC & & $\checkmark$ & $\checkmark$ & $\checkmark$ & $\checkmark$ & & & $\checkmark$ & $\checkmark$ & $\checkmark$ & $\checkmark$ & & & $\checkmark$ & 64.28 & 9 \\
\hline Diagram de Ishikawa & $\checkmark$ & $\checkmark$ & $\checkmark$ & $\checkmark$ & $\checkmark$ & $\checkmark$ & $\checkmark$ & $\checkmark$ & $\checkmark$ & $\checkmark$ & $\checkmark$ & $\checkmark$ & & $\checkmark$ & 92.86 & 13 \\
\hline FMEA & $\checkmark$ & $\checkmark$ & $\checkmark$ & $\checkmark$ & $\checkmark$ & & $\checkmark$ & $\checkmark$ & $\checkmark$ & $\checkmark$ & $\checkmark$ & $\checkmark$ & & $\checkmark$ & 85.72 & 12 \\
\hline Histogram/Pareto & $\checkmark$ & $\checkmark$ & $\checkmark$ & $\checkmark$ & $\checkmark$ & $\checkmark$ & $\checkmark$ & $\checkmark$ & $\checkmark$ & $\checkmark$ & $\checkmark$ & $\checkmark$ & $\checkmark$ & $\checkmark$ & 100 & 14 \\
\hline Poka Yoke & & $\checkmark$ & $\checkmark$ & $\checkmark$ & $\checkmark$ & $\checkmark$ & & $\checkmark$ & $\checkmark$ & $\checkmark$ & & $\checkmark$ & & $\checkmark$ & 71.45 & 10 \\
\hline QFD & & $\checkmark$ & $\checkmark$ & & & & & & & & $\checkmark$ & & $\checkmark$ & $\checkmark$ & 35.71 & 5 \\
\hline SMD & & $\checkmark$ & $\checkmark$ & $\checkmark$ & & $\checkmark$ & & $\checkmark$ & $\checkmark$ & $\checkmark$ & $\checkmark$ & & $\checkmark$ & $\checkmark$ & 71.45 & 10 \\
\hline \multicolumn{17}{|l|}{ Programs } \\
\hline 5S Program & $\checkmark$ & $\checkmark$ & $\checkmark$ & $\checkmark$ & $\checkmark$ & $\checkmark$ & $\checkmark$ & & $\checkmark$ & $\checkmark$ & $\checkmark$ & $\checkmark$ & $\checkmark$ & & 85.72 & 12 \\
\hline BSC & & $\checkmark$ & $\checkmark$ & $\checkmark$ & & & $\checkmark$ & $\checkmark$ & $\checkmark$ & $\checkmark$ & & $\checkmark$ & & & 57.14 & 8 \\
\hline Lean production & $\checkmark$ & $\checkmark$ & $\checkmark$ & $\checkmark$ & & $\checkmark$ & & & $\checkmark$ & $\checkmark$ & & & & & 57.14 & 8 \\
\hline Cleaner Production & & $\checkmark$ & $\checkmark$ & $\checkmark$ & & $\checkmark$ & & & $\checkmark$ & $\checkmark$ & & $\checkmark$ & $\checkmark$ & & 57.14 & 8 \\
\hline Six Sigma & $\checkmark$ & $\checkmark$ & $\checkmark$ & $\checkmark$ & & $\checkmark$ & & $\checkmark$ & $\checkmark$ & $\checkmark$ & $\checkmark$ & & $\checkmark$ & & 64.28 & 9 \\
\hline
\end{tabular}

Table 7

GLOSSARY: Some frequently used terms.

5S (Serei, Seiton, Seiso, Seiketsu, Shitsuke): 5 S is a simple tool for organizing the workplace in a clean, efficient and safe manner to enhance productivity, visual management and to ensure the introduction of standardized work.

5W1H or 5W2H (What, When, Where, Who, Why, How and How Much): The 5W1H (in some cases, used as 5W2H) is a management model widely used in the business environment to organize a set of planned actions. For each problem identified, analyzed and prioritized, it is necessary to develop a specific action plan to solve it.

Balanced Scorecard (BSC): A Balanced Scorecard is a performance metric used in strategic management to identify and improve various internal functions of a business and its external performance resulting. It is used to measure and provide feedback to organizations.

Failure Mode and Effects Analysis (FMEA): Failure modes and effects analysis (FMEA) is a step-by-step approach for identifying all possible failures in a design, in a manufacturing or assembly process, or in a product or service. The purpose of the FMEA is to take actions to eliminate or reduce failures, starting with the highestpriority ones.

Poka Yoke: Japanese approach to 'mistake proofing' in all aspects of manufacturing, customer service, procurement, etc. It employs visual signals that make the mistakes are clearly detached from the rest or devices that stop an assembly line or process if a part or step is missed.

Quality Control Circles (QCC): Quality control circle is a group of employees who do the same or similar work, whom meet regularly to identify, analyze and solve workrelated problems. Normally small in size, the group is usually led by a supervisor or manager and presents solutions to management. Where possible, workers also implement their own solutions in order to improve the performance of the organization and motivate employees.

Quality Function Deployment (QFD): Means listening to voice of the market (customer). It is a structured product development process which translates what the market requires into a program to create, manufacture, and deliver it. In a QFD process, multi-skilled teams collaborate to arrive at a common understanding of the customer needs and determine the appropriate technical requirements of each stage.

Six Sigma: Six Sigma is a management philosophy that utilizes a set of tools and techniques to improve business processes. It emphasizes setting extremely high objectives, collecting data and analyzing results to a fine degree as a way to reduce defects in products and services. At many organizations, the Six Sigma process is used as a way to measure quality and strive for perfection.

Single Minute Exchange of Die (SMED): Is a system for dramatically reducing the time it takes to complete equipment changeovers. The essence of the SMED system is to convert as many changeover steps as possible to "external" (performed while the equipment is running), and to simplify and streamline the remaining steps. The name Single-Minute Exchange of Dies comes from the goal of reducing changeover times to the "single" digits (i.e. less than 10 min).

Statistical Process Control (SPC): Also called statistical quality control, it is an application of statistical methods and procedures (such as control charts) to analyze the inherent variability of a process or its outputs to achieve and maintain a state of statistical control, and to improve the process capability.

Benchmarking was detected as structurally practiced to take place in the form of projects and is supported by the quality teams' experience. Although FMEA is a more complex tool, it is also widely used by the companies studied, which have considerable availability of resources for develop the use of more sophisticated tools and programs.

The Poka Yoke, SMED (Single Minute Exchange of Die), used $71.45 \%$ of the companies (10 companies), the SPC (Statistical Process Control), used by $64.29 \%$ of the companies ( 9 companies), QCC (Quality Control Circles) and Quality Teams, used by 8 or $57.14 \%$ of the companies are another examples of tools used by a substantial number of companies. QCC's has structural quality elements and helps to guarantee the adequacy to one of the quality principles, the continuous improvement. However, SPC, Poka Yoke and SMED are more specific instruments that contribute to error prevention of and process optimization.

In $35.71 \%$ of the companies studied (5 companies), the QFD (Quality Function Deployment) was proved to be the least used tool. The companies explained the main barrier to use of this tool is its complexity and, consequently, the difficulty in finding professionals with knowledge and sufficient experience to use it.

About the programs, it was observed that they are less used than the tools. 5S (Serei, Seiton, Seiso, Seiketsu, Shitsuke) and Six Sigma are the most used programs by the companies studied (used, respectively, by 12 and 10 companies that represents $85.72 \%$ and $71.54 \%$ of the total). These programs are considered an extension of the quality theory, which since the establishment of standards and stricter restrictions on variations is based on projects managed by experts, although with the direct participation of those who effectively act in the process aimed at being improved.

The BSC (Balanced Scorecard), Lean Production and Cleaner Production, used by $57.14 \%$ of the companies (eight companies), are programs that have considerable interfaces with certifiable management systems and, therefore, can leverage their bases to be developed, or vice versa.

Therefore, certifiable management systems have many elements in common, which support themselves and/or are interdependent. Its systemic and joint management provides many benefits for the companies. The IMS guarantees that several procedures, such as inspections, audits, training, records, etc., are not duplicated, 
generating considerable savings. These factors enable significant competitive advantages to the organizations that go beyond the benefits that each of these systems individually generates.

Considering the amount of procedures, integrated functions and their good practices, it was verified that $35.71 \%$ of the companies (A, $\mathrm{B}, \mathrm{H}, \mathrm{K}$ and $\mathrm{M}$ ) are the most advanced concerning integration. In contrast, $28.57 \%$ (E, F, G and L) were observed to have low intensity of integration. Finally, from an overview of the data presented in this section, it is concluded that all the companies studied have QMS, EMS and OHSMS individually well-developed, but few have the MSs operating in an integrated manner.

\section{Conclusion}

The objective of this article is to characterize and discuss the elements and functions most commonly integrated in Brazilian companies certified by the management systems ISO 9001, ISO 14001 and OHSAS 18001 and to identify the benefits and difficulties from integration.

The main findings of this study were: 1 ) The companies were motivated to experience the integration by a self-evaluation of the company, which showed them the benefits of an IMS; 2) The benefits of integration identified in the companies studied were: improvement in the efficiency of operations and internal communication, greater agility in the decision-making process, increase in the quality of goods and services produced or provided and increase in the reliability of the products and processes; 3 ) The main difficulties faced during the integration process were: complexity of integration process and high amount of human and financial resources to integration be achieved; 4) The most commonly integrable elements and functions in an IMS were: high management responsibility, work instructions, control of documents and records, internal communication, structure and accountability and finally, 5) The tools and programs most used in integrated context were: brainstorming, histogram and Pareto chart.

As have been argued throughout this article, information about the elements that are effectively integrated in an IMS is commonly presented secondarily in studies that present the integration and approaches about the levels of integration of IMS. Thus, it is highlighted that other works in this field deal with it from a more general view, without consider a detailed focus as presented in this article.

Based on the case studies analyses we also could observe that the certified management systems ISO 9001, ISO 14001 and OHSAS 18001 have been consolidated as instruments capable of transforming the companies that adopt them. Moreover, the findings showed that the IMS implementation has emerged as a good solution to improve the efficiency of the operations and internal communication, to provide greater agility in the decision-making process, increase the quality of goods and services produced or provided and increase in the reliability of the products and processes.

This study academically contributes with suggestions of achievements to overcome the major difficulties and challenges faced during the integration process. As the main applied contribution of this work, it is emphasized that the findings can be used as a guide for industrial companies that want to integrate their certifiable management systems independently and contribute with consulting firms to improve their customer support processes.

Therefore, the research novelty is precisely the systematization, identification and articulation of the elements and functions most commonly integrated, which will facilitate the integration process by businesses and the development of further studies.

However, some limitations are worth to be considered as, for example, the fear of companies to release information and the impossibility of generalizing the results of case studies. The fact that there is no organ that concentrates information about companies with triple certification (ISO 9001, ISO 14001 and OHSAS) was another difficulty faced in the research development.

In order to check the degree of integration of the elements and functions presented in this article, it is suggested to be carried out in future studies a survey in a statistically larger group considering the different methodologies of integration adopted by the companies, so that the results obtained can be generalized.

\section{Acknowledgements}

Coordination for the Improvement of Brazilian Higher Education (CAPES).

\section{References}

Abad, J., Lafuente, E., Vilajosana, J., 2013. An assessment of the OHSAS 18001 certification process: objective drivers and consequences on safety performance and labour productivity. Saf. Sci. 60, 47-56.

Al-Najjar, S.M., 2011. ISO 9001 implementation barriers and misconceptions: an empirical study. Int. J. Bus. Adm. 2, 1923-4007.

Bernardo, M., Casadesús, M., Heras, I., 2009. Management audits: an empirical study. Dirección Organ. 39, 37-44.

Bernardo, M., Simon, A., Tarí, J.J., Molina-Azorín, J.F., 2015. Benefits of management systems integration: a literature review. J. Clean. Prod. 94, 260-267.

Boiral, O., 2011. Managing with ISO systems: lessons from practice. Long Range Plan. 44, 197-220.

Campos, L.M.S., Heizen, D.A.M., Verdinelli, M.A., Miguel, P.A.C., 2015. Environmental performance indicators: a study on ISO 14001 certified companies. J. Clean. Prod. 99, 286-296.

Ferrón, V.V., Darnall, N., 2016. Two are better than one: the link between management systems and business performance. Bus. Strategy Environ. EconPapers 25, 221-240.

Guikema, S., Milke, M., 1999. Quantitative decision tool for conservation programme planning: practice, theory and potential. Environ. Conserv. 26, 179-189.

ISO Survey, 2016. International organization for Standardization (Accessed 03 April 2016). http://www.iso.org.

Ivanova, A., Gray, J., Sinha, K., 2014. Towards a unifying theory of management standard implementation. Int. J. Operations Prod. Manag. 34, 1269-1306.

Jupp, V., 2006. The Sage Dictionary of Social Research Methods. Sage Publications Ltd., New York, pp. 79-249.

Karapetrovic, S., Casadesús, M., 2009. Implementing environmental with other standardized management systems: scope, sequence, time and integration. J. Clean. Prod. 17, 533-540.

Kim, D.Y., Kumar, V., Kumar, U., 2012. Relationship between quality management practices and innovation. J. Operations Manag. 30, 295-315.

Kim, Y.H., Sting, F.J., Loch, C.H., 2014. Top-down, bottom-up, or both? Toward an integrative perspective on operations strategy formation. J. Operations Manag. $32,462-474$

Kothari, C., 2013. Research Methodology: Methods and Techniques, third ed. New Aged International Publishers, New Delhi.

Lo, K.Y., Pagell, M., Di Fran, C., Wiengarten, F., Yeung, A.C.L., 2014. OHSAS 18001 certification and operating performance: the role of complexity and coupling. J. Operations Manag. 32, 268-280.

Magd, D., Nabulsi, F., 2012. The effectiveness of ISO 9000 in an emerging market as a business process management tool: the case of the UAE. Proced. Econ. Finance 3, 158-165.

Naveh, E., Marcus, A., 2004. When does the ISO 9000 quality assurance standard lead to performance improvement? Assimilation and going beyond. IEEE Trans. Eng. Manag. 51, 352-363.

OHSAS. Occupational Health and Safety Assessments Series, 2016. http://www 18001.org (Accessed 03 April 2016).

Oliveira, O.J., 2013. Guidelines for the integration of certifiable management systems in industrial companies. J. Clean. Prod. 57, 124-133.

Pronovost, P.J., Marsteller, J.A., 2014. Creating a fractal-based quality management infrastructure. J. Health Organ. Manag. 28, 576-586.

Qi, G., Zeng, S., Yin, H., Lin, H., 2013. ISO and OHSAS certifications: How stakeholders affect corporate decisions on sustainability. Manag. Decis. 51, 1983-2005.

Rebelo, M.F., Santos, G., Silva, R., 2014. A generic model for integration of quality, environment and safety management systems. TQM J. 26, 143-159.

Salomone, R., 2008. Integrated management systems: experiences in Italian organizations. J Clean. Prod. 16, 1786-1806.

Sampaio, P., Neves, A., 2012. Integrated management systems quality, environment and safety - implementation and evaluation of efficiency. TMQ Tech. Methodol. Qual. 3, 130-145.

Sampaio, P., Saraiva, P., Domingues, P., 2012. Management systems: integration or addition? Int. J. Qual. Reliab. Manag. 29, 402-424.

Santos, G., Síria, B., Mendes, F., Lopes, N., 2013. The main benefits associated with health and safety management systems certification in Portuguese small and 
medium enterprises post quality management system certification. Saf. Sci. 51 29-36.

Searcy, C., Morali, O., Karapetrovic, S., 2012. An analysis of ISO 14001 and suggested improvements. J. Glob. Responsib. 3, 278-293.

Simon, A., Karapetrovic, S., Casadesús, M., 2012. Difficulties and benefits of integrated management systems. Industrial Manag. Data Syst. 112, 828-846.

Simon, A., Yaya, L.H.P., Karapetrovic, S., Casadesús, M., 2014a. An empirical analysis of the integration of internal and external management system audits. J. Clean. Prod. 66, 499-506.

Simon, A., Yaya, L.H.P., Karapetrovic, S., Casadesús, M., 2014b. Can integration difficulties affect innovation and satisfaction? Ind. Manag. Data Syst. 114, 183-202.

Stravos, C., Westberg, K., 2009. Using triangulation and multiple case studies to advance relationship marketing theory. Qual. Mark. Res. Int. J. 12, 307-320.

Sumaedi, S., Yarmen, M., 2015. The effectiveness of ISO 9001 implementation in food manufacturing companies: a proposed measurement instrument. Proced. Food Sci. 3, 436-444.

Testa, F., Rizzi, F., Daddi, T., Gusmerotti, N.M., Fabio Iraldo, M.F., 2014. EMAS and ISO
14001: the differences in effectively improving environmental performance. J. Clean. Prod. 68, 165-173.

Vrellas, C.G., Tsiotras, G., 2015. Quality management in the global brewing industry. Int. J. Qual. Reliab. Manag. 32, 42-52.

Weckenmann, A., Akkasoglu, G., Werner, T., 2015. Quality management - history and trends. TQM J. 27, 281-293.

Wening, S.K., Refflinghaus, R., 2015. Integrating sustainability aspects into an integrated management system. TQM J. 27, 303-315.

Yin, R.K., 2014. Case Study Research: Design and Methods, fifth ed. SAGE Publications, New York.

Zeng, S.X., Shi, J.J., Lou, G.X., 2007. A synergetic model for implementing an integrated management system: an empirical study in China. J. Clean. Prod. 15, 1760-1767.

Zhao, M., Cheng, C., Chau, K., Li, G., 2006. Multiple criteria data envelopment analysis for full ranking units associated to environment impact assessment. Int. J. Environ. Pollut. 28, 448-464. 